\title{
Saliva and dental erosion
}

\author{
Marília Afonso Rabelo BUZALAF ${ }^{1}$, Angélicas Reis HANNAS ${ }^{2}$, Melissa Thiemi KATO
}

1- DDS, MSc, PhD, Full Professor, Discipline of Biochemistry, Department of Biological Sciences, Bauru School of Dentistry, University of São Paulo, Bauru, SP, Brazil.

2- DDS, MSc, PhD, Department of Biological Sciences, Bauru School of Dentistry, University of São Paulo, Bauru, SP, Brazil.

3- DDS, MSc, PhD student, Department of Biological Sciences, Bauru School of Dentistry, University of São Paulo, Bauru, SP, Brazil.

Corresponding address: Profa. Dra. Marília Afonso Rabelo Buzalaf - Faculdade de Odontologia de Bauru - USP - Departamento de Ciências Biológicas - Al. Octávio Pinheiro Brisolla, 9-75. Bauru-SP - 17012-901 - Brasil - Phone: + 5514 3235-8346 - Fax + 55 14 $3227-1486$ - e-mail: mbuzalaf@fob.usp.br

Received: September 8, 2010 - Modification: October 8, 2011 - Accepted: November 2, 2011

\section{ABSTRACT}

\begin{abstract}
D ental erosion is a multifactorial condition. The consideration of chemical, biological and behavioral factors is fundamental for its prevention and therapy. Among the biological factors, saliva is one of the most important parameters in the protection against erosive wear. Objective: This review discusses the role of salivary factors on the development of dental erosion. Material and Methods: A search was undertaken on MEDLINE website for papers from 1969 to 2010. The keywords used in the research were "saliva", "acquired pellicle", "salivary flow", "salivary buffering capacity" and "dental erosion". Inclusion of studies, data extraction and quality assessment were undertaken independently and in duplicate by two members of the review team. Disagreements were solved by discussion and consensus or by a third party. Results: Several characteristics and properties of saliva play an important role in dental erosion. Salivary clearance gradually eliminates the acids through swallowing and saliva presents buffering capacity causing neutralization and buffering of dietary acids. Salivary flow allows dilution of the acids. In addition, saliva is supersaturated with respect to tooth mineral, providing calcium, phosphate and fluoride necessary for remineralization after an erosive challenge. Furthermore, many proteins present in saliva and acquired pellicle play an important role in dental erosion. Conclusions: Saliva is the most important biological factor affecting the progression of dental erosion. Knowledge of its components and properties involved in this protective role can drive the development of preventive measures targeting to enhance its known beneficial effects.
\end{abstract}

Key words: Dental erosion. Enamel. Dentin. Saliva.

\section{INTRODUCTION}

Dental erosion is defined as the loss of dental hard tissue by a chemical process that does not involve bacteria ${ }^{87}$. The continuous erosion process occurs in different stages. Initially, softening of enamel surface occurs and this process can vary according to the immersion time and the type of acids involved. If the erosive challenge persists, dissolution of consecutive layers of enamel crystals takes place, leading to a permanent loss of volume with a softened layer on top of the remaining tissue ${ }^{69}$. Dental erosion can have extrinsic or intrinsic causes. The intrinsic causes comprise recurrent vomiting as in patients suffering from anorexia and bulimia, cytostatic drug treatment or propulsion of gastric contents into the mouth due to gastroesophageal reflux. Extrinsic causes comprise frequent consumption of acidic foods or drinks, the use of acidic hygiene products and acidic medicines. such as effervescent vitamin C or aspirin. Alcohol has been also associated with erosion. Gaseous acids or chemicals breathed during work may also cause erosion ${ }^{78}$.

In enamel, the lesion primarily develops in the prism sheath areas, followed by dissolution of prism cores. Eventually, the interprismatic areas are also affected. Bulk mineral is centripetally etched away in enamel erosion leaving a partly demineralized softened surface layer, which is prone to mineral deposits after topical fluoride application ${ }^{18}$. In dentin, erosive demineralization results in the exposure of an outer layer of fully demineralized organic matrix followed by a partly demineralized 
zone until the sound inner dentin is reached ${ }^{55}$. There are several physiological factors that may modify the erosive process both ways, i.e. they may either protect against erosion or increase the degree of erosion. These include saliva, tooth composition and structure, dental anatomy and occlusion, anatomy of soft tissues in relation to teeth, and physiological movements like swallowing ${ }^{116}$.

One of the main biological parameters is saliva. It provides protection against acid erosion by different ways ${ }^{35,36,40,67,83}$. First, there is the influence of the acquired pellicle 37,40 . Second, saliva presents a diluent action over the acids. Third, salivary clearance gradually eliminates the acids through swallowing. Fourth, saliva presents buffering capacity causing neutralization and buffering of dietary acids. Fifth, saliva is supersaturated with respect to tooth mineral content, providing calcium, phosphate and fluoride necessary for remineralization. Sixth, many proteins present in saliva and acquired pellicle play an important role on dental erosion (Figure 1 ).

In this literature review, we discuss these key issues that relate saliva to dental erosion, focusing on the development of preventive measures that rely on salivary composition, characteristics and properties. This will help the reader to better understand the role of saliva as the most important biological factor related to the development of dental erosion, allowing the translation of this information to the clinical situation.

\section{MATERIAL AND METHODS}

In order to review the role of saliva on the development of dental erosion, a search was undertaken on MEDLINE website for papers from 1969 to 2011 . The keywords used in the research were "saliva", "acquired pellicle", "salivary flow",

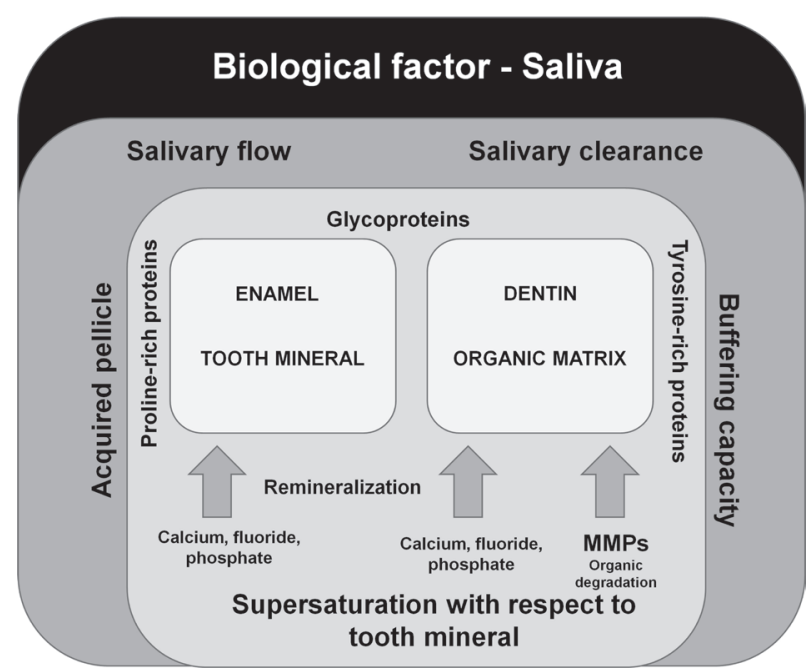

Figure 1- Salivary factors associated with the control of dental erosion in enamel and dentin "salivary buffering capacity" and "dental erosion". The titles and abstracts were first screened before the full-text articles were considered. Only Englishand Portuguese-language research papers were selected. Inclusion of studies, data extraction and quality assessment were undertaken independently and in duplicate by two members of the review team. Disagreements were solved by discussion and consensus or by a third party. In order to organize the central ideas, the text was divided into the following sections: salivary composition, acquired pellicle, salivary flow and buffering capacity, salivary clearance, remineralization and the relationship between metalloproteinases of matrix (MMPs) and dental erosion.

\section{Salivary composition}

Saliva is secreted by three pairs of major salivary glands (parotid, submandibular and sublingual) plus numerous minor salivary glands ${ }^{100}$. This fluid is constituted by inorganic and organic components. Among the inorganic components, bicarbonate is related to saliva buffering capacity, while calcium and phosphate allow for maintenance of tooth mineral integrity.

In the organic composition, there are a number of proteins and glycoproteins in human saliva that may influence several aspects of oral health ${ }^{14}$. Many of these proteins contain high levels (35-40\%) of proline, and are therefore, designated proline-rich proteins (PRPs), which comprise almost $70 \%$ of the total protein content of human parotid saliva. Since amylase comprises most of the remainder of the total protein content of parotid saliva, the other proteins (such as lysozyme, lactoferrin, peroxidase, and secretory IgA) that have received more attention in attempted linkages between saliva and oral health are, in fact, relatively minor components ${ }^{14}$.

Statherin allows saliva to maintain its state of supersaturation with respect to calcium and phosphate salts. Thus, these protein components contribute greatly to the maintenance of an intact dentition through their binding and inhibition of spontaneous calcium phosphate precipitation and crystal growth, while at the same time providing possibilities for heterogeneities in microbial colonization through their specific bacterial binding patterns ${ }^{25,26}$.

Intact histatins have been identified in in vivo formed acquired pellicle and have been attributed to possess anti-demineralization properties when phosporilated. It appears that binding of intact histatins to the enamel surface occurs prior to their proteolytic degradation, and that binding to the mineral exerts a protective effect against further enzymatic proteolytic degradation ${ }^{96}$.

Mucins, the major organic component of 
submandibular/ sublingual saliva, are large glycoproteins. Their high degree of glycosylation and potential for hydration prevent desiccation while their viscoelastic properties provide lubrication. They may also bind to toxins, agglutinate bacteria, interact with host cells, and are important components of the acquired pellicle and plaque matrix $^{84}$. Salivary mucins have been reported to contribute to a large extent to the protective effect of the acquired pellicle against enamel erosion ${ }^{84}$.

Saliva also contains matrix metalloproteinases (MMPs) that have been recently implicated in the progression of erosion ${ }^{51-53,73}$, which will be discussed later.

Knowing the role of organic components of saliva on the protection against dental erosion, it would be important to assess the concentration of these potentially protective components in patients at high risk to develop erosion, as well as to determine if these values are different from a normal healthy reference population.

\section{Acquired pellicle}

All solid surfaces exposed to the oral cavity are covered by a proteinaceous layer referred to as the acquired pellicle $e^{33,35,39,63}$. It is an organic film free of bacteria that covers oral hard and soft tissues. It is composed of glycoproteins and proteins, including several enzymes ${ }^{33}$. Using liquid chromatography-electrospray-ionization tandem mass spectrometry (LC-ESI-MS/MS), a total of 130 different proteins have been identified in in vivo collected human acquired enamel pellicle and at least 89 of these could be identified in at least 3 experiments ${ }^{97}$. Among the identified proteins, only $14.4 \%$ derived from exocrine salivary glands, while $67.8 \%$ derived from cells and $17.8 \%$ originated from serum, coming through the crevicular fluid. If these proteins are grouped based on their possible role in the acquired pellicle formation, they can be separated into three main groups: proteins that have ability to bind calcium ions $(17.5 \%)$, those that show a high tendency to bind phosphate ions $(15.4 \%)$, which may form the primary protein layer that adsorbs to the enamel surface and finally those that can interact with other proteins (28.2\%). The last ones are possibly involved in the formation of successive protein layers by interacting with proteins directly adsorbed onto the enamel surface. Regarding their biological functions, the identified proteins are involved in inflammatory response $(12.5 \%)$, antimicrobial $(8.3 \%)$ and immune defense $(11.3 \%)$, lubrication $(<1 \%)$, buffer $(<1 \%)$ and remineralization $(15.5 \%)$ capacities. The presence of proteins covering enamel and involved in lubrication, buffer and remineralization processes makes acquired pellicle an important factor related to the etiology of dental erosion. It serves as a diffusion barrier or a perm-selective membrane, preventing direct contact between acids and the tooth surface ${ }^{35}$, and thus inhibiting its demineralization ${ }^{1,36}$.

The acquired pellicle may protect against erosion by acting as a diffusion barrier or a perm-selective membrane, preventing direct contact between the acids and tooth surface, thus reducing the dissolution rate of dental hard tissue ${ }^{37,40}$. It is important to highlight that in most in vitro studies, the researchers employ artificial saliva and most of the formulations lack salivary proteins, thus not allowing the adequate formation of acquired pellicles, which has an impact on the erosive process. Ideally, in vitro erosion models should incorporate exposure to natural human saliva what is not an easy task ${ }^{109}$, since collection of natural saliva is time consuming and this fluid decomposes quickly ${ }^{1}$. It is noteworthy that greater amount of intact proteins has been detected within in vitro pellicles compared with in vivo or in situ pellicles ${ }^{115}$. This implies that maturation processes might occur during in vivo pellicle formation and enzymes immobilized in the pellicle such as transglutaminase have been shown to be involved in this process ${ }^{34}$, with impact on the protective properties of the pellicle. Additionally, the composition of the pellicle layer can be affected by the diet. It has been demonstrated that rinse with milk or kappa-casein changes the number and molecular weight of the proteins deposited in the acquired pellicle, when compared with rinse with water $^{104}$. Following this rationale, addition of casein to acid solutions and soft drinks has been shown to reduce their erosive potential ${ }^{42}$.

Recently, several studies have focused on the protective impact of the in situ formed acquired pellicle on enamel surfaces $35-38,42$. Pellicle layers formed in situ for $0.5,1$ and $2 \mathrm{~h}^{37}$ or 2, 6, 12 and $24 \mathrm{~h}^{38}$, respectively, do not differ significantly in their ability to reduce enamel demineralization. However, acid resistance of the pellicle layer itself seems to be dependent on formation time, since the $2 \mathrm{~h}$ pellicle dissolves from the enamel surface more rapidly compared with 6,12 and 24 h pellicles ${ }^{38}$.

Compared with enamel, information regarding the role of dentin pellicle on erosion is more limited. In a previous in situ study conducted over 14 days, it was shown that saliva offered better protection against erosion of enamel than of dentin. Significantly less enamel and dentin loss could therefore be observed for samples stored in situ compared with storage in water or saliva in vitro $^{30}$. Due to the different composition of dental hard tissues it may be assumed that the protective properties of the pellicle can vary for enamel and dentin erosion. A recent study found a protective, but limited, effect of the acquired pellicle on dentin surfaces $^{31}$. The thickness of the demineralized dentin 
surface after 5 min of acid contact was not different for pellicle-free and pellicle-covered samples, but the presence of the pellicle significantly reduced calcium loss of the dentin samples ${ }^{31}$. In contrast, Hara, et al. ${ }^{40}$ (2006) showed that an intraoral pellicle formed for $2 \mathrm{~h}$ was not effective in reducing dentin softening induced by an excessive acid challenge (1,030 min, orange juice). However, the lack of protective effect found in this case might have been due to the high erosive challenge employed.

As different acids vary in their ability to demineralize bovine enamel ${ }^{32}$, the protection of the in situ formed pellicle on enamel and dentin erosion caused by hydrochloric, citric and phosphoric acid was analyzed ${ }^{112}$. Bovine enamel and dentin samples were exposed for $120 \mathrm{~min}$ in the oral cavity of 10 healthy volunteers. Subsequently, enamel and dentin pellicle-covered specimens were extraorally immersed in $1 \mathrm{~mL}$ hydrochloric, citric or phosphoric acid ( $\mathrm{pH} 2.6,60 \mathrm{~s}$, each acid $\mathrm{n}=30$ samples). Pellicle-free samples (each acid $\mathrm{n}=10$ ) served as controls. Calcium release into the acid was determined by atomic absorption spectroscopy. Pellicle-covered samples showed significantly less calcium loss compared with pellicle-free samples in all acid groups. The mean $( \pm S D)$ pellicle protection (\% reduction of calcium loss) was significantly better for enamel samples $(60.9 \pm 5.3)$ than for dentin samples (30.5 \pm 5.0$)$, but revealed no differences among the acids. The efficacy of the in situ pellicle in reducing erosion was 2-fold better for enamel than for dentin. Protection of the pellicle was not influenced by the kind of acid when enamel and dentin erosion was performed at $\mathrm{pH}$ 2.6. A reduction of calcium loss of between $59.8 \%$ and $77.5 \%$ for enamel samples eroded by $1 \%$ citric acid for $60 \mathrm{~s}$ has been detected ${ }^{37,38}$. The overall protection of dentin $(30.5 \%)$, obtained by integrating the results of the three different acids, is in accordance with previous results ${ }^{32}$, which showed a reduction of calcium erosion of about $27 \%$ after treatment with hydrochloric acid ( $\mathrm{pH} 2.3,5 \mathrm{~min})$. Another in vitro study also showed that salivary pellicle offered proportionately greater protection for enamel $(44 \%)$ than for dentin $(14 \%)^{111}$.

The study by Wiegand, et al. ${ }^{112}$ (2008) allowed for direct comparison of the pellicle effects on erosion of enamel and dentin. It might be assumed that differences in the enamel or dentin structure could affect the composition or adsorption of the acquired pellicle ${ }^{27}$ and, thus, the protective efficacy of the pellicle. The protective potential of the enamel salivary pellicle is attributed to its ability to act to some extent as a diffusion barrier as well as a semi-permeable membrane ${ }^{38}$. The higher porosity and solubility of dentin compared with enamel led to a faster demineralization, which might prevent the pellicle from acting as a protective barrier $^{40}$. It has been also speculated that saliva penetrates the tubule system of dentin to produce not only a pellicle layer on the surface but a meniscus of viscous liquid at the tubule orifices ${ }^{114}$. Further studies are necessary to analyze possible differences in the composition and structure of the acquired pellicle on enamel and dentin which might be responsible for the different protection. However, it cannot be excluded that the protective capacity of the pellicle and the difference between enamel and dentin protection might be less evident under severe erosive conditions, as that used by Hara, et al. ${ }^{40}$ (2006)

Taking into account the great number of proteins that have been already identified in the acquired pellicle and its protective role against dental erosion, studies should focus on investigating which pellicle components are more associated with this protective role. Thus, preventive therapies should attempt to enrich the pellicle with these proteins in order to enhance its protective potential.

\section{Salivary flow and buffering capacity}

Clinical experience with patients suffering from salivary flow alterations demonstrates the importance of saliva. Studies have shown that erosion may be associated with low salivary flow or/and low buffering capacity $48,68,91$. Dry mouth condition is usually related to aging ${ }^{14,82,86}$, even though other studies have not found this correlation ${ }^{4,41}$. It is well established that patients taking medication can also present decreased saliva output ${ }^{114}$, as well as those who have received radiation therapy for neck and head cancer ${ }^{15}$. Tests of the stimulated and unstimulated flow rate and buffering capacity of saliva may provide some information about the susceptibility of an individual to dental erosion. However, it has to be kept in mind that these parameters are only two of a multifactorial condition ${ }^{66}$. Studies have shown that sour diet have a strong influence on the anticipatory salivary flow ${ }^{8,62}$, which can be significantly increased when compared with the normal unstimulated flow rate ${ }^{16}$. Hypersalivation also occurs in advance of vomiting and can be observed in individuals suffering from anorexia and bulimia nervosa, rumination and chronic alcoholism. It has been suggested that this could minimize erosion caused by gastric acids ${ }^{66}$. The same is not valid for patients suffering from gastroesophageal reflux disease because in this case the response is involuntary and not coordinated by the autonomic nervous system. Thus, there may be insufficient time for saliva to play its role before erosion occurs ${ }^{92}$.

Salivary flow may also to be reduced in cases of vigorous exercising due dehydration that may be induced by enhanced elimination of body fluids ${ }^{65}$. Association between sport activities and 
erosive tooth wear has been reported 44,45 . The cause could be direct acid exposure or strenuous exercise, which may increase gastroesophageal reflux. Also swimmers exercising in water that has a low $\mathrm{pH}$ and athletes who frequently consume erosive sports drinks have increased risk to develop erosive lesions. Furthermore, sports drinks are often erosive $\mathrm{e}^{44,45,99,106}$ and their consumption during strenuous activity when the person has already some degree of dehydration may enhance the possible destructive effects.

Some systemic diseases may affect salivary flow. For instance, in Sjögren Syndrome, a chronic autoimmune disorder, saliva levels of gelatinase and collagenase increase because of a chronic inflammation deriving from an autoimmune disease, which affects the salivary glands, reducing salivary flow rate and increasing caries incidence ${ }^{58,113}$ with a probable impact on the prevalence of erosion. It has been reported that patients submitted to radiation therapy have decreased salivary flow rate, buffering capacity and salivary $\mathrm{pH}$, what in turn is correlated with active salivary MMP-9 ${ }^{108}$. As discussed below, the activity of Matrix Metalloproteinases (MMPs) might be related to a faster progression of erosion.

Salivary flow stimulation can yield an increase in bicarbonate buffer and in salivary mineral content, which can facilitate calcium and phosphate redeposition onto the enamel and dentin surfaces and reduce dental tissues loss ${ }^{10}$. Rios, et al. ${ }^{89}$ (2006) showed that saliva stimulated by the use of sugar-free chewing gum promoted a remineralizing action in the erosive/abrasive phenomena. Increased salivary clearance also reduces intrinsic erosion. It was shown that chewing sugar-free gum for 30 minutes after a meal can reduce acidic postprandial esophageal reflux ${ }^{81}$. In contrast, sucking of acidic candies might change the whole saliva composition so that it may have erosive potential ${ }^{49}$. The remineralizing effect of saliva might be increased by rinsing with milk or eating cheese, which are of interest because they contain higher levels of calcium and phosphate than water or saliva and, therefore, may act as donors of calcium and phosphate for remineralization ${ }^{22}$. Although the consumption of milk or cheese or chewing gum can be recommended to enhance the rehardening of demineralized dental hard tissues, only few studies investigated their effects on enamel demineralization as yet ${ }^{21-23}$.

Besides local saliva stimulators, such as chewing gum, the salivary flow rate can also be increased systemically. Thus, patients suffering from xerostomia are often treated by cholinergic drugs, such as pilocarpine. Moreover, saliva substitutes might provide relief of the oral symptoms. Saliva substitutes should be of neutral $\mathrm{pH}$ to prevent demineralization of the dental hard tissues and should be saturated with respect to calcium and phosphate to gain remineralizing potential ${ }^{79}$.

\section{Salivary clearance}

Salivary clearance is the process by which substances are removed from the oral cavity ${ }^{100}$. The act of swallowing and salivary flow directly influence salivary clearance. When dietary substances such as sugar or acid are ingested, they stimulate salivary flow if they are concentrated above the taste threshold. This shortens the half-time until the flow rate reaches the unstimulated flow rate. There is a correlation between a decreased salivary flow rate and the capacity to clear acidic substances from the mouth 67,93 .

In patients with reduced salivary flow rate, acid clearance is reduced, and less dilution of acid will be present upon attack of the tooth surface, contributing to erosion progress especially where there is a direct contact with the acid. This happens because the acid clearance is the most rapid in that location and the salivary film velocity is the highest in the mouth. Therefore, after a person consumes acid, the Stephan curves at those places will be shallow, and saliva will tend to remain undersaturated with respect to the tooth minerals ${ }^{11}$.

The clearance rate may be influenced by the position of the tooth in the mouth. When the $\mathrm{pH}$ at the surface of teeth of healthy volunteers after drinking $1 \%$ citric acid was monitored ${ }^{80}$, it was observed that the $\mathrm{pH}$ recovered to above $\mathrm{pH} 5.5$ within two minutes from a site adjacent to the palatal surface of the upper central incisor and within four-to-five minutes from the other palatal surface of the upper first molar. More recent observations have revealed a longer clearance time on the upper incisors for patients with active erosions compared with patients with no erosion ${ }^{65}$. These differences could be due to the anatomy of the teeth and soft tissues, which may influence the retention and clearance patterns of erosive agents. Also, soft tissue movements of the tongue and buccal mucosa and the swallowing pattern can influence the clearance rate. The importance of the tongue in modifying the tooth-wear process has long been subject of speculation 28,65 .

\section{Remineralization}

The most important factors in the repair of softened enamel are saliva and fluoride ${ }^{46}$. Acidsoftened enamel can reharden after exposure to saliva or to a remineralization solution and dietary substances and fluoride may enhance the remineralization process ${ }^{1,18,22}$. Nevertheless, some in situ investigations could not detect a significant rehardening effect of saliva ${ }^{9,20,23,64}$, while others have reported a beneficial effect of salivary stimulation with a sugar-free chewing gum ${ }^{89}$ on rehardening of 
eroded and eroded/abraded enamel.

Calcium and phosphate, as well as an alkaline or neutral environment are prerequisites for remineralization. Calcium and phosphate levels in saliva act as common ions to the minerals in enamel and dentin, resulting in a slower dissolution rate of mineral78. Supersaturation of saliva with respect to apatite is possible due to the presence of the proline-rich proteins and a tyrosine-rich protein (statherin) which are able to inhibit calcium and phosphate precipitation ${ }^{29,95}$. Salivary proteins have been shown to bind to dissolution sites and to cover crystallites by specific adsorption ${ }^{107}$

Fluoride is well recognized to enhance remineralization and greatly reduce demineralization under mild acidic environments as happens in cariogenic challenges. Due to fluoride's effective action to reduce caries, its use to prevent erosive enamel loss has been proposed ${ }^{3}$. In the case of dental erosion, however, no subsurface lesion is available for remineralization, and therefore the precipitation of $\mathrm{CaF}_{2}$-like layers can be assumed to be the only mode of action of fluoride. However, the protective effect of fluoride on erosion is controversial ${ }^{60}$. Promising results to inhibit erosion have only been obtained in the presence of high fluoride concentrations ${ }^{2,61}$. It was demonstrated that enamel exposed to erosive conditions is more susceptible to abrasion, but after being exposed to artificial saliva, the eroded enamel became more resistant to abrasion ${ }^{2}$. In saliva, however, $\mathrm{CaF}_{2}$ is less soluble than in water or in phosphate buffer ${ }^{94}$ and $\mathrm{CaF}_{2}$-like precipitates can therefore be observed for several weeks after application, if a sufficient amount is deposited initially ${ }^{13}$. This saliva-induced remineralization is a slow process that may be enhanced by fluoride application. The onset of a more stable $\mathrm{CaF}_{2}$-like layer on the enamel surface results from the application of high-concentration fluoride agents, such as oral rinses, gels or varnishes which have been demonstrated to increase abrasion resistance and decrease the development of enamel and dentin erosion in vitro and in situ ${ }^{59,74}$. Most studies focusing on the preventive effect of fluoride on erosion used fluoride compounds which have been used over years in caries prevention, such as $\mathrm{NaF}, \mathrm{AmF}, \mathrm{SnF}_{2}$ or acidulated phosphate fluoride (APF) (12.300 to 22.600 ppm F, pH 1.0 to 7.0). Although the results of an in vitro study by Ganss, et al. ${ }^{19}$ (2008) suggest considerable differences among $\mathrm{NaF}, \mathrm{AmF}$ and $\mathrm{SnF}_{2}$, the impact of different fluoride compounds on erosion was not analyzed under clinical conditions yet. The efficacy of fluorides to affect de- and remineralization is related to its concentration and depends on the $\mathrm{pH}$ of the fluoride agent. It is known that the formation of a $\mathrm{CaF}_{2}$ reservoir is increased under acidic compared with neutral conditions. Depending on the design of the study, the application of high-concentration fluoride agents might lead to a nearly complete reduction of dental erosion ${ }^{74}$.

In contrast to the application of highly fluoridated agents, a 1,000 ppm $\mathrm{F}$ dentifrice was shown to have a limited beneficial effect compared with non-fluoridated dentifrices on abrasion of eroded dentin and enamel ${ }^{71,88,90}$. However, in a recent in situ study, it was shown that a 5,000 ppm F dentifrice had the same effect as a 1,100 ppm F dentifrice on eroded and eroded and abraded dentin. Also for enamel wear, no significant differences were found among 1,100 and 5,000 ppm F dentifrices ${ }^{90}$. In general, the efficacy of a fluoridated dentifrice does not increase along with the $\mathrm{F}$ concentration in dentifrices containing more than 1,000 ppm $\mathrm{F}$ and the reduction of wear seems to be less than $30 \%$ for this fluoride vehicle compared with placebo ${ }^{71,90}$.

In conclusion, high-concentration fluoride agents and/or frequent applications seems to be effective to prevent dental erosion and this protective effect might be more effective in enamel than in dentin ${ }^{72}$.

\section{MMPs and erosion}

MMPs are the major enzymes responsible for the degradation of almost all proteins of the extracellular matrix. It is believed that most MMPs from saliva come from gingival crevicular fluid ${ }^{47,98,103,110}$. However, other studies suggest that at least gelatinases (MMP-2 and MMP-9) are also secreted by the parotid gland 75 . MMPs are also present in whole saliva ${ }^{47,75,103}$ and dentin ${ }^{76,77,101}$.

In dentin, the erosive demineralization results in the exposure of an outer layer of fully demineralized organic matrix followed by a partly demineralized zone until the sound inner dentin is reached ${ }^{55}$. Dentin demineralization rate decreases when the amount of degradable collagen increases. It is believed that the demineralized matrix hampers ionic diffusion into and out of the demineralizing area $^{56,57}$. Dentin organic matrix can be degraded both mechanically and chemically. Chemically, it can be degraded by MMPs that are a family of zinc-dependent proteolytic enzymes degrading extracellular matrix proteins, including different collagens in native and denatured forms ${ }^{5}$. The activation of MMPs seems to play a role in dentinal erosion progression, since they have a crucial role in the collagen breakdown that leads to progression of dentin caries lesions ${ }^{102}$. Various MMPs-including at least MMP-2, 8, -9 and -20 are present in human dentinal caries lesions ${ }^{101,102}$. Dentin matrix contains mainly type I collagen, and salivary MMPs degrade this matrix after demineralization ${ }^{102}$. Intact human dentin also contains latent mammalian collagenase ${ }^{12}$ and MMP- $2^{50,76,77}$. In addition, individuals with a high concentration of MMPs in saliva present an increased susceptibility to dental caries ${ }^{6}$. Also 
MMP-8 present in saliva may negatively influence the remineralization of demineralized dentin ${ }^{85}$. Furthermore, MMPs can be activated by lowering the $\mathrm{pH}$ to 4.5 , followed by neutralization ${ }^{102}$, as it occurs during the carious process when the $\mathrm{pH}$ in dental plaque drops within minutes after sugar ingestion until neutralized by salivary buffers. The same rationale was recently applied to dental erosion, leading to a series of in situ studies.

In the first study, the protective effect of a green tea rinse after erosive challenges against erosion and erosion associated to abrasion (immediate or after $30 \mathrm{~min}$ ) was evaluated. Regardless the experimental condition, the green tea rinse significantly reduced the wear compared with water rinse. For both treatments, the wear was significantly higher when abrasion was performed immediately after erosion compared with erosion alone. Only when rinsing was performed with water (control), delayed abrasion (30 min) led to significantly higher wear than erosion alone ${ }^{53}$.

In a subsequent study it was not tested plain green tea, but a green tea extract containing $30 \%$ epigallocatechin-gallate (EGCG) (OM24 ${ }^{\mathrm{Tm}}$, $100 \%$ Camellia sinensis leaf extract, $\mathrm{pH} 7.0$, Omnimedica AG. Schlieren, Switzerland), as well as chlorhexidine digluconate $(0.06 \%$ chlorhexidine, $\mathrm{pH}$ 6.0, Periogard ${ }^{\circledR}$; Colgate-Palmolive, São Bernardo do Campo, SP, Brazil) as rinse solutions in the prevention of erosion. Water was used as a negative control and Meridol (250 ppm fluoride, Gaba, Müchenstein, Switzerland), as a positive control. All solutions significantly reduced the dentin wear by $30-50 \%$ when compared with control for both conditions (erosion and erosion associated to abrasion). Despite green tea extract and chlorhexidine solution led to lesser wear when compared with fluoride solution, the differences between these solutions were not significant ${ }^{73}$.

In the next step, the active principle in green tea (pure EGCG at concentrations of 10 and 400 $\mu \mathrm{M})$ and also chlorhexidine $(0.012 \%)$ were tested. These concentrations are known to inhibit MMP-2 and -9 . Additionally, the contact time of the active substances with dentin was increased by using the products in the form of gels. The gels were applied on the dentin blocks for $1 \mathrm{~min}$ before starting the erosive challenges only once. The erosive challenges were essentially the same employed in the two above-mentioned studies ${ }^{53,73}$. A negative control (gel without any active principle) and a positive control (gel containing $1.23 \% \mathrm{~F}$ ). The positive control (F) reduced erosion in more than $50 \%$, but it was not significantly different from placebo. The gels containing MMP inhibitors completely inhibited erosion ${ }^{51}$. The same was observed when a gel containing $\mathrm{FeSO}_{4}$, which was shown to inhibit MMP-2 and MMP-9, was used ${ }^{52}$. The proposed role of MMP inhibition on the decrease of dentin erosion progression is illustrated in Figure 2.

The inhibitory effect of chlorhexidine on MMPs is attributed to a chelating mechanism, since the inhibition of MMP-2 and MMP-9 could be prevented by the addition of calcium chloride chlorhexidine. It was also discussed that chlorhexidine might interfere with essential sulfhydryl groups and/or cysteine present in the active site of $\mathrm{MMPs}^{24}$. As for the inhibitory effect of EGCG on MMPs, it is believed that this polyphenol might interact with the enzyme by hydrogen bonding and hydrophobic interactions,

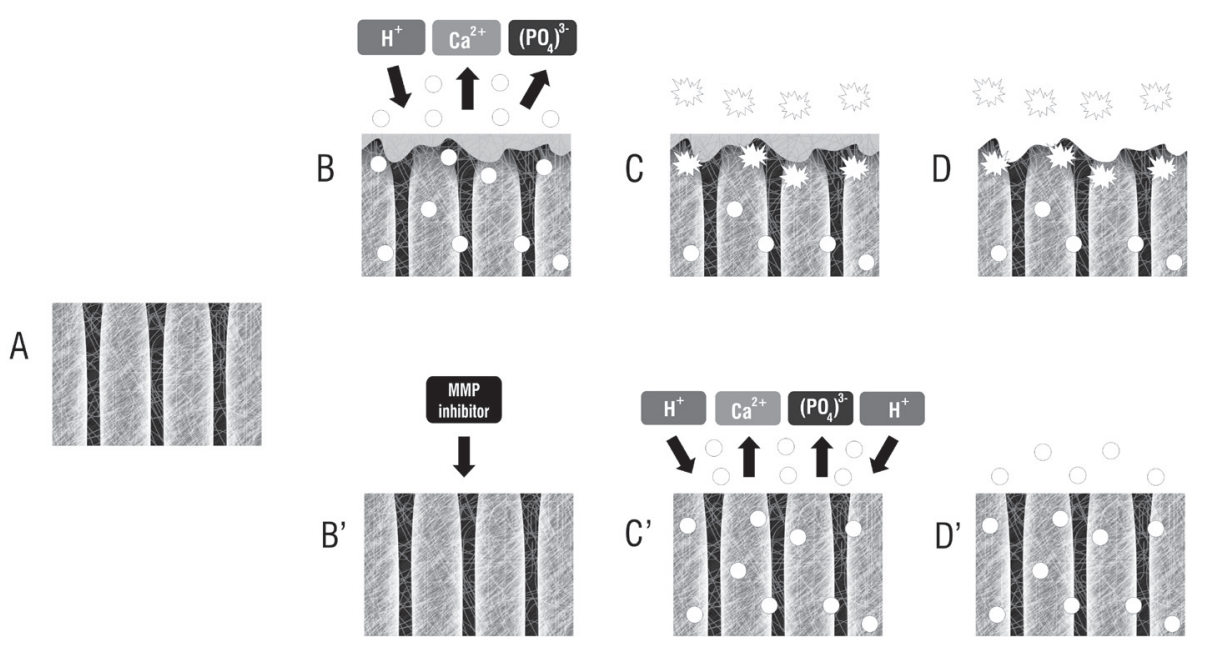

Figure 2- Proposed mechanism of action of Matrix Metalloproteinases (MMPs) on dentin erosion. Spheres: inactive MMP. Asterisk shapes: active MMP. (A) Sound dentin. After the erosive challenge, the dentin surface is demineralized (B), causing the exposure of the collagen fibrils (C). When unprotected by a MMP inhibitor, the collagen fibrils are exposed by the action of the acid of the soft drink and the collagen fibrils hydrolysed (C, D). By the inhibition of dentin-bound and/or salivary MMPs (B'), the preserved organic layer prevents further demineralization during the subsequent erosive challenges (C'), resulting in a significant decrease in erosive wear (D'). Illustration modified from Kato, et al..$^{52}$ (2010) 
which might lead to conformational changes or to masking of the catalytic region of MMP- $2^{7,70}$. Regarding ferrous sulphate, it is believed that metal ions bind to specific sites, causing conformational changes that inactivate the catalytic function of enzymes ${ }^{52}$.

The results of this series of studies indicate that inhibition of MMPs (either dentin- or saliva-derived), preserving the demineralized organic matrix, seems to be effective to prevent dentin erosion. However, a proof-of-concept study is still necessary to confirm these findings. If this demineralized layer can be remineralized is still a matter of debate, since the literature is contradictory $43,54,105$. Further studies should be carried out in an attempt to access the longevity of the effect on wear reduction, to establish clinical protocols and to evaluate the possibility of remineralization of the demineralized organic layer, thus allowing complete reconstitution of the eroded dentin.

\section{CONCLUSIONS}

Saliva is the most important biological factor affecting the progression of dental erosion. Knowledge of its components and properties involved in this protective role can drive the development of preventive measures targeting to enhance its known beneficial effects. On this regard, new approaches to prevent dentin erosion should take advantage of protective salivary components and properties. It is necessary that the information derived from in vitro and in situ studies is confirmed by clinical studies, which is not an easy task, due to the difficulty in finding response variables that can be reliably employed in the clinical situation.

\section{ACKNOWLEDGEMENTS}

We would like to thank FAPESP (Grants 07/08389-3, 07/04209-0 and 08/09857-3) and CNPq (557863/2008-2) for supporting our studies on dental erosion.

\section{REFERENCES}

1- Amaechi BT, Higham SM. Eroded enamel lesion remineralization by saliva as a possible factor in the site-specificity of human dental erosion. Arch Oral Biol. 2001;46:697-703.

2- Attin T, Knöfel S, Buchalla W, Tütüncü R. In situ evaluation of different remineralization periods to decrease brushing abrasion of demineralized enamel. Caries Res. 2001;35:216-22.

3- Bartlett DW, Smith BG, Wilson RF. Comparison of the effect of fluoride and non-fluoride toothpaste on tooth wear in vitro and the influence of enamel fluoride concentration and hardness of enamel. Br Dent J. 1994;176:346-8.

4- Ben-Aryeh H, Shalev A, Szargel R, Laor A, Laufer D, Gutman $D$. The salivary flow rate and composition of whole and parotid resting and stimulated saliva in young and old healthy subjects. Biochem Med Metab Biol. 1986;36:260-5.
5- Birkedal-Hansen $\mathrm{H}$. Proteolytic remodeling of extracellular matrix. Curr Opin Cell Biol. 1995;7:728-35.

6- Chaussain-Miller C, Fioretti F, Goldberg M, Menashi S. The role of matrix metalloproteinases (MMPs) in human caries. J Dent Res. 2006;85:22-32.

7- Cheng XW, Kuzuya M, Kanda S, Maeda K, Sasaki T, Wang $\mathrm{QL}$, et al. Epigallocatechin-3-gallate binding to MMP-2 inhibits gelatinolytic activity without influencing the attachment to extracellular matrix proteins but enhances MMP-2 binding to TIMP-2. Arch Biochem Biophys. 2003;415:126-32.

8- Christensen CM, Navazesh M. Anticipatory salivary flow to the sight of different foods. Appetite. 1984;5:307-15.

9- Collys K, Cleymaet R, Coomans D, Michotte Y, Slop D. Rehardening of surface softened and surface etched enamel in vitro and by intraoral exposure. Caries Res. 1993;27:15-20.

10- Dawes $C$. The effects of flow rate and duration of stimulation on the concentrations of protein and the main electrolytes in human parotid saliva. Arch Oral Biol. 1969;14:277-94.

11- Dawes C. Salivary flow patterns and the health of hard and soft oral tissues. J Am Dent Assoc. 2008;139:18S-24S.

12- Dayan D, Binderman I, Mechanic GL. A preliminary study of activation of collagenase in carious human dentine matrix. Arch Oral Biol. 1983;28:185-7.

13- Dijkman AG, de Boer $P$, Arends J. In vivo investigation on the fluoride content in and on human enamel after topical applications. Caries Res. 1983;17:392-402.

14- Dodds MW, Johnson DA, Yeh CK. Health benefits of saliva: a review. J Dent. 2005;33:223-33.

15- Dreizen S, Brown LR, Daly TE, Drane JB. Prevention of xerostomia-related dental caries in irradiated cancer patients. J Dent Res. 1977;56:99-104.

16- Engelen L, de Wijk RA, Prinz JF, van der Bilt A, Bosman F. The relation between saliva flow after different stimulations and the perception of flavor and texture attributes in custard desserts. Physiol Behav. 2003;78:165-9.

17- Feagin F, Koulourides T, Pigman W. The characterization of enamel surface demineralization, remineralization, and associated hardness changes in human and bovine material. Arch Oral Biol. 1969;14:1407-17.

18- Ganss C, Klimek J, Schäffer U, Spall T. Effectiveness of two fluoridation measures on erosion progression in human enamel and dentine in vitro. Caries Res. 2001;35:325-30.

19- Ganss C, Schlueter N, Hardt M, Schattenberg P, Klimek J. Effect of fluoride compounds on enamel erosion in vitro: a comparison of amine, sodium and stannous fluoride. Caries Res. 2008;42:2-7. 20- Garberoglio R, Cozzani G. In vivo effect of oral environment on etched enamel: a scanning electron microscopic study. J Dent Res. 1979;58:1859-65.

21- Gedalia I, Braustein E, Lewinstein I, Shapira L, Ever-Hadani P, Sela M. Fluoride and hard cheese exposure on etched enamel in neck-irradiated patients in situ. J Dent. 1996;24:365-8.

22- Gedalia I, Dakuar A, Shapira L, Lewinstein I, Goultschin J, Rahamim E. Enamel softening with Coca-Cola and rehardening with milk or saliva. Am J Dent. 1991;4:120-2.

23- Gedalia I, Ionat-Bendat D, Ben-Mosheh S, Shapira L. Tooth enamel softening with a cola type drink and rehardening with hard cheese or stimulated saliva in situ. J Oral Rehabil. 1991;18:501-6. 24- Gendron R, Grenier D, Sorsa T, Mayrand D. Inhibition of the activities of matrix metalloproteinases 2,8 , and 9 by chlorhexidine. Clin Diagn Lab Immunol. 1999;6:437-9.

25- Gibbons RJ, Hay DI. Adsorbed salivary proline-rich proteins contribute to the adhesion of Streptococcus mutans JBP to apatitic surfaces. J Dent Res. 1989;68:1303-7.

26- Gibbons RJ, Hay DI, Cisar JO, Clark WB. Adsorbed salivary proline-rich protein 1 and statherin: receptors for type 1 fimbriae of Actinomyces viscosus T14V-J1 on apatitic surfaces. Infect Immun. 1988;56:2990-3.

27- Glantz PO, Baier RE, Christersson CE. Biochemical and physiological considerations for modeling biofilms in the oral cavity: a review. Dent Mater. 1996;12:208-14. 
28- Gregg T, Mace S, West NX, Addy M. A study in vitro of the abrasive effect of the tongue on enamel and dentine softened by acid erosion. Caries Res. 2004;38:557-60.

29- Gron P, Hay DI. Inhibition of calcium phosphate precipitation by human salivary secretions. Arch Oral Biol. 1976;21:201-5.

30- Hall AF, Buchanan CA, Millett DT, Creanor SL, Strang R, Foye $\mathrm{RH}$. The effect of saliva on enamel and dentine erosion. J Dent. 1999;27:333-9.

31- Hannig C, Becker K, Häusler N, Hoth-Hannig W, Attin T, Hannig $M$. Protective effect of the in situ pellicle on dentin erosion - an ex vivo pilot study. Arch Oral Biol. 2007;52:444-9.

32- Hannig C, Hamkens A, Becker K, Attin R, Attin T. Erosive effects of different acids on bovine enamel: release of calcium and phosphate in vitro. Arch Oral Biol. 2005;50:541-52.

33- Hannig C, Hannig M, Attin T. Enzymes in the acquired enamel pellicle. Eur J Oral Sci. 2005;113:2-13.

34- Hannig C, Spitzmüller B, Miller M, Hellwig E, Hannig M. Intrinsic enzymatic crosslinking and maturation of the in situ pellicle. Arch Oral Biol. 2008;53:416-22.

35- Hannig M, Balz M. Influence of in vivo formed salivary pellicle on enamel erosion. Caries Res. 1999;33:372-9.

36- Hannig M, Balz M. Protective properties of salivary pellicles from two different intraoral sites on enamel erosion. Caries Res. 2001;35:142-8

37- Hannig M, Fiebiger $M$, Güntzer $M$, Döbert A, Zimehl R, Nekrashevych Y. Protective effect of the in situ formed short-term salivary pellicle. Arch Oral Biol. 2004;49:903-10.

38- Hannig M, Hess NJ, Hoth-Hannig W, De Vrese M. Influence of salivary pellicle formation time on enamel demineralization - an in situ pilot study. Clin Oral Investig. 2003;7:158-61.

39- Hannig $M$, Joiner $A$. The structure, function and properties of the acquired pellicle. Monogr Oral Sci. 2006;19:29-64.

40- Hara AT, Ando M, González-Cabezas C, Cury JA, Serra MC, Zero DT. Protective effect of the dental pellicle against erosive challenges in situ. J Dent Res. 2006;85:612-6.

41- Heintze $U$, Birkhed D, Björn $H$. Secretion rate and buffer effect of resting and stimulated whole saliva as a function of age and sex. Swed Dent J. 1983;7:227-38.

42- Hemingway CA, White AJ, Shellis RP, Addy M, Parker DM, Barbour ME. Enamel erosion in dietary acids: Inhibition by food proteins in vitro. Caries Res. 2010;44:525-30.

43- Hiraishi N, Sono R, Islam MS, Otsuki M, Tagami J, Takatsuka $\mathrm{T}$. Effect of hesperidin in vitro on root dentine collagen and demineralization. J Dent. 2011;39:391-6.

44- Hooper S, West NX, Sharif N, Smith S, North M, De'Ath J, et al. A comparison of enamel erosion by a new sports drink compared to two proprietary products: a controlled, crossover study in situ. J Dent. 2004;32:541-5.

45- Hooper SM, Hughes JA, Newcombe RG, Addy M, West NX. A methodology for testing the erosive potential of sports drinks. J Dent. 2005;33:343-8.

46- Imfeld T. Dental erosion. Definition, classification and links. Eur J Oral Sci. 1996;104:151-5.

47- Ingman T, Sorsa T, Lindy O, Koski H, Konttinen YT. Multiple forms of gelatinases/type IV collagenases in saliva and gingival crevicular fluid of periodontitis patients. J Clin Periodontol. 1994;21:26-31.

48- Järvinen VK, Rytömaa II, Heinonen OP. Risk factors in dental erosion. J Dent Res. 1991;70:942-7.

49- Jensdottir T, Nauntofte B, Buchwald C, Bardow A. Effects of sucking acidic candy on whole-mouth saliva composition. Caries Res. 2005;39:468-74.

50- Kato MT, Hannas AR, Leite AL, Bolanho A, Zarella BL, Santos J, et al. Activity of MMPs in bovine versus human dentine. Caries Res. 2011;45:429-34.

51- Kato MT, Leite AL, Hannas AR, Buzalaf MA. Gels containing MMP inhibitors prevent dental erosion in situ. J Dent Res. 2010;89:468-72.
52- Kato MT, Leite AL, Hannas AR, Oliveira RC, Pereira JC, Tjäderhane $L$, et al. Effect of iron on matrix metalloproteinase inhibition and on the prevention of dentine erosion. Caries Res. 2010;44:309-16.

53- Kato MT, Magalhães AC, Rios D, Hannas AR, Attin T, Buzalaf $M A$. Protective effect of green tea on dentin erosion and abrasion. ] Appl Oral Sci. 2009;17:560-4.

54- Kim DS, Kim J, Choi KK, Kim SY. The influence of chlorhexidine on the remineralization of demineralized dentine. J Dent. 2011;39:855-62.

55- Kinney JH, Balooch M, Haupt DL Jr., Marshall SJ, Marshall GW Jr. Mineral distribution and dimensional changes in human dentin during demineralization. J Dent Res. 1995;74:1179-84.

56- Kleter GA, Damen JJ, Everts V, Niehof J, Ten Cate JM. The influence of the organic matrix on demineralization of bovine root dentin in vitro. J Dent Res. 1994;73:1523-9.

57- Klont B, Ten Cate JM. Remineralization of bovine incisor root lesions in vitro: the role of the collagenous matrix. Caries Res. $1991 ; 25: 39-45$.

58- Konttinen $Y$, Kangaspunta $P$, Lindy O, Takagi M, Sorsa T, Segerberg $M$, et al. Collagenase in Sjögren's syndrome. Ann Rheum Dis. 1994;53:836-9.

59- Lagerweij MD, Buchalla W, Kohnke S, Becker K, Lennon AM, Attin T. Prevention of erosion and abrasion by a high fluoride concentration gel applied at high frequencies. Caries Res. 2006;40:148-53.

60- Larsen MJ. Prevention by means of fluoride of enamel erosion as caused by soft drinks and orange juice. Caries Res. 2001;35:229-34.

61- Larsen MJ, Richards A. Fluoride is unable to reduce dental erosion from soft drinks. Caries Res. 2002;36:75-80.

62- Lee VM, Linden RW. An olfactory-submandibular salivary reflex in humans. Exp Physiol. 1992;77:221-4.

63- Lendenmann U, Grogan J, Oppenheim FG. Saliva and dental pellicle - a review. Adv Dent Res. 2000;14:22-8.

64- Lippert F, Parker DM, Jandt KD. In vitro demineralization/ remineralization cycles at human tooth enamel surfaces investigated by AFM and nanoindentation. J Colloid Interface Sci. 2004;280:442-8.

65- Lussi A, Hellwig E, Ganss C, Jaeggi T. Buonocore Memorial Lecture. Dental erosion. Oper Dent. 2009;34:251-62.

66- Lussi A, Jaeggi T. Erosion - diagnosis and risk factors. Clin Oral Investig. 2008;12:S5-13.

67- Lussi A, Jaeggi T, Zero D. The role of diet in the aetiology of dental erosion. Caries Res. 2004;38:34-44.

68- Lussi A, Schaffner M. Progression of and risk factors for dental erosion and wedge-shaped defects over a 6-year period. Caries Res. 2000;34:182-7.

69- Lussi A, Schlueter N, Rakhmatullina E, Ganss C. Dental erosion - an overview with emphasis on chemical and histopathological aspects. Caries Res. 2011;45:2-12.

70- Madhan B, Krishnamoorthy G, Rao JR, Nair BU. Role of green tea polyphenols in the inhibition of collagenolytic activity by collagenase. Int J Biol Macromol. 2007;41:16-22.

71- Magalhães AC, Rios D, Delbem AC, Buzalaf MA, Machado MA. Influence of fluoride dentifrice on brushing abrasion of eroded human enamel: an in situ/ex vivo study. Caries Res. 2007;41:77-9. 72- Magalhães AC, Wiegand A, Rios D, Buzalaf MA, Lussi A. Fluoride in dental erosion. Monogr Oral Sci. 2011;22:158-70.

73- Magalhães AC, Wiegand A, Rios D, Hannas A, Attin T, Buzalaf MA. Chlorhexidine and green tea extract reduce dentin erosion and abrasion in situ. J Dent. 2009;37:994-8.

74- Magalhães AC, Wiegand A, Rios D, Honório HM, Buzalaf MA. Insights into preventive measures for dental erosion. J Appl Oral Sci. 2009;17:75-86.

75- Mäkelä M, Salo T, Uitto VJ, Larjava H. Matrix metalloproteinases (MMP-2 and MMP-9) of the oral cavity: cellular origin and relationship to periodontal status. J Dent Res. 1994;73:1397-406. 
76- Martin-De Las Heras S, Valenzuela A, Overall CM. The matrix metalloproteinase gelatinase $A$ in human dentine. Arch Oral Biol. 2000;45:757-65.

77- Mazzoni A, Mannello F, Tay FR, Tonti GA, Papa S, Mazzotti G, et al. Zymographic analysis and characterization of MMP-2 and -9 forms in human sound dentin. J Dent Res. 2007;86:436-40. 78- Meurman JH, Ten Cate JM. Pathogenesis and modifying factors of dental erosion. Eur J Oral Sci. 1996;104:199-206.

79- Meyer-Lückel H, Kielbassa AM. Influence of calcium phosphates added to mucin-based saliva substitutes on bovine dentin. Quintessence Int. 2006;37:537-44.

80- Millward A, Shaw L, Harrington E, Smith AJ. Continuous monitoring of salivary flow rate and $\mathrm{pH}$ at the surface of the dentition following consumption of acidic beverages. Caries Res. 1997;31:44-9.

81- Moazzez R, Bartlett D, Anggiansah A. The effect of chewing sugar-free gum on gastro-esophageal reflux. J Dent Res. 2005;84:1062-5.

82- Navazesh M, Mulligan RA, Kipnis V, Denny PA, Denny PC. Comparison of whole saliva flow rates and mucin concentrations in healthy Caucasian young and aged adults. J Dent Res. $1992 ; 71: 1275-8$.

83- Nieuw Amerongen AV, Bolscher JG, Veerman EC. Salivary proteins: protective and diagnostic value in cariology? Caries Res. 2004;38:247-53.

84- Nieuw Amerongen AV, Oderkerk $\mathrm{CH}$, Driessen AA. Role of mucins from human whole saliva in the protection of tooth enamel against demineralization in vitro. Caries Res. 1987;21:297-309. 85- Nordbø H, Leirskar J, Ngo H, Mount GJ, Wahlgren J. The influence of a matrix metalloproteinase on the remineralization of artificially demineralized dentin. Oral Health Prev Dent. 2003; 1:267-72.

86- Percival RS, Challacombe SJ, Marsh PD. Flow rates of resting whole and stimulated parotid saliva in relation to age and gender. J Dent Res. 1994;73:1416-20.

87- Pindborg JJ. Pathology of the dental hard tissues. Philadelphia: Saunders; 1970. p. 274-320.

88- Ponduri S, Macdonald E, Addy M. A study in vitro of the combined effects of soft drinks and tooth brushing with fluoride toothpaste on the wear of dentine. Int J Dent Hyg. 2005;3:7-12. 89- Rios D, Honório HM, Magalhães AC, Delbem AC, Machado MA, Silva SM, et al. Effect of salivary stimulation on erosion of human and bovine enamel subjected or not to subsequent abrasion: an in situ/ex vivo study. Caries Res. 2006;40:218-23.

90- Rios D, Magalhães AC, Polo RO, Wiegand A, Attin T, Buzalaf MA. The efficacy of a highly concentrated fluoride dentifrice on bovine enamel subjected to erosion and abrasion. J Am Dent Assoc. 2008;139:1652-6.

91- Rytömaa I, Järvinen V, Kanerva R, Heinonen OP. Bulimia and tooth erosion. Acta Odontol Scand. 1998;56:36-40.

92- Saksena R, Bartlett DW, Smith BG. The role of saliva in regurgitation erosion. Eur J Prosthodont Restor Dent. 1999;7:1214.

93- Sanchez GA, Fernandez De Preliasco MV. Salivary pH changes during soft drinks consumption in children. Int J Paediatr Dent. 2003;13:251-7.

94- Saxegaard E, Rölla G. Fluoride acquisition on and in human enamel during topical application in vitro. Scand J Dent Res. 1988;96:523-35.

95- Schlesinger DH, Hay DI. Complete covalent structure of statherin, a tyrosine-rich acidic peptide which inhibits calcium phosphate precipitation from human parotid saliva. J Biol Chem. 1977;252:1689-95.

96- Siqueira WL, Margolis HC, Helmerhorst EJ, Mendes FM, Oppenheim FG. Evidence of intact histatins in the in vivo acquired enamel pellicle. J Dent Res. 2010;89:626-30.

97- Siqueira WL, Zhang W, Helmerhorst EJ, Gygi SP, Oppenheim FG. Identification of protein components in in vivo human acquired enamel pellicle using LC-ESI-MS/MS. J Proteome Res. 2007;6:2152-60.
98- Sorsa T, Ding YL, Ingman T, Salo T, Westerlund U, Haapasalo $M$, et al. Cellular source, activation and inhibition of dental plaque collagenase. J Clin Periodontol. 1995;22:709-17.

99- Sorvari R, Pelttari A, Meurman JH. Surface ultrastructure of rat molar teeth after experimentally induced erosion and attrition. Caries Res. 1996;30:163-8.

100- Sreebny LM: Saliva in health and disease: an appraisal and update. Int Dent J. 2000;50:140-61.

101- Sulkala M, Wahlgren J, Larmas M, Sorsa T, Teronen O, Salo T, et al. The effects of MMP inhibitors on human salivary MMP activity and caries progression in rats. J Dent Res. 2001;80:1545-9.

102- Tjäderhane L, Larjava $H$, Sorsa $T$, Uitto VJ, Larmas M, Salo $\mathrm{T}$. The activation and function of host matrix metalloproteinases in dentin matrix breakdown in caries lesions. ] Dent Res. $1998 ; 77: 1622-9$.

103- Uitto VJ, Suomalainen K, Sorsa T. Salivary collagenase. Origin, characteristics and relationship to periodontal health. J Periodontal Res. 1990;25:135-42.

104- Vacca Smith AM, Bowen WH. The effects of milk and kappacasein on salivary pellicle formed on hydroxyapatite discs in situ. Caries Res. 2000;34:88-93.

105- Van Strijp AJ, Gerardu VA, Buijs MJ, van Loveren C, ten Cate JM. Chlorhexidine efficacy in preventing lesion formation in enamel and dentine: an in situ study. Caries Res. 2008;42:460-5. 106- Venables $M C$, Shaw $L$, Jeukendrup $A E$, Roedig-Penman $A$, Finke $M$, Newcombe RG, et al. Erosive effect of a new sports drink on dental enamel during exercise. Med Sci Sports Exerc. 2005;37:39-44.

107- Voegel JC, Belcourt A, Gillmeth S. Dissolution of hydroxyapatites treated with salivary glycoproteins and fluoride. Caries Res. 1981;15:243-9.

108- Vuotila T, Ylikontiola L, Sorsa T, Luoto H, Hanemaaijer R, Salo $\mathrm{T}$, et al. The relationship between MMPS and $\mathrm{pH}$ in whole saliva of radiated head and neck cancer patients. J Oral Pathol Med. 2002;31:329-38.

109- West NX, Davies M, Amaechi BT. In vitro and in situ erosion models for evaluating tooth substance loss. Caries Res. 2011;45:43-52.

110- Westerlund $U$, Ingman T, Lukinmaa PL, Salo T, Kjeldsen L, Borregaard $\mathrm{N}$, et al. Human neutrophil gelatinase and associated lipocalin in adult and localized juvenile periodontitis. J Dent Res. 1996;75:1553-63.

111- Wetton S, Hughes J, West N, Addy M. Exposure time of enamel and dentine to saliva for protection against erosion: a study in vitro. Caries Res. 2006;40:213-7.

112- Wiegand A, Bliggenstorfer S, Magalhães AC, Sener B, Attin $\mathrm{T}$. Impact of the in situ formed salivary pellicle on enamel and dentine erosion induced by different acids. Acta Odontol Scand. 2008;66:225-30.

113- Wu AJ. Production of matrix metalloproteinases in Sjögren's syndrome. J Dent Res. 1996;75(Spec Iss):271.

114- Wynn RL, Meiller TF. Drugs and dry mouth. Gen Dent. 2001;49:10-2,14.

115- Yao Y, Grogan J, Zehnder M, Lendenmann U, Nam B, Wu Z, et al. Compositional analysis of human acquired enamel pellicle by mass spectrometry. Arch Oral Biol. 2001;46:293-303.

116- Zero DT. Etiology of dental erosion - extrinsic factors. Eur J Oral Sci. 1996;104:162-77. 